\title{
Comparison of load shifting incentives for low-energy buildings with heat pumps to attain grid flexibility benefits
}

\author{
Dieter Patteeuw ${ }^{\mathrm{a}, \mathrm{c}, *}$, Gregor P. Henze ${ }^{\mathrm{b}}$, Lieve Helsen ${ }^{\mathrm{a}, \mathrm{c}, *}$ \\ ${ }^{a}$ KU Leuven Energy Institute, Division Applied Mechanics and Energy Conversion, Department of Mechanical \\ Engineering, KU Leuven, Celestijnenlaan 300 box 2420, B-3001 Leuven, Belgium \\ ${ }^{b}$ Dept. of Civil, Environmental and Architectural Engineering, University of Colorado, Boulder, Colorado, USA \\ ${ }^{c}$ EnergyVille, Thor Park, Waterschei, Belgium
}

\begin{abstract}
This paper aims at assessing the value of load shifting and demand side flexibility for improving electric grid system operations. In particular, this study investigates to what extent residential heat pumps participating in load shifting can contribute to reducing operational costs and $\mathrm{CO}_{2}$ emissions associated with electric power generation and how home owners with heat pump systems can be best motivated to achieve these flexibility benefits. Residential heat pumps, when intelligently orchestrated in their operation, can lower operational costs and $\mathrm{CO}_{2}$ emissions by performing load shifting in order to reduce curtailment of electricity from renewable energy sources and improve the efficiency of dispatchable power plants. In order to study the interaction, both the electricity generation system and residences with heat pumps are modeled. In a first step, an integrated modeling approach is presented which represents the idealized case where the electrical grid operation in terms of unit commitment and dispatch is concurrently optimized with that of a large number of residential heat pumps located in homes designed to low-energy design standards. While this joint optimization approach does not lend itself for real-time implementation, it serves as an upper bound for the achievable operational cost savings. The main focus of this paper is to assess to what extent load shifting incentives are able to achieve the aforementioned savings potential. Two types of incentives are studied: direct load control and dynamic time-of-use pricing. Since both the electricity generation supply system and the residential building stock with heat pumps had been modeled for the joint optimization, the performance of both load shifting incentives can be compared by separately assessing the supply and demand side. Superior performance is noted for the direct-load control scenario, achieving $60 \%$ to $90 \%$ of the cost savings attained in the jointly optimized best-case scenario. In dynamic time-of-use pricing, poor performance in terms of reduced cost and emissions is noted when the heat pumps response is not taken into account. When the heat pumps response is taken into account, dynamic time-of-use pricing performs better. However, both dynamic time-of-use pricing schemes show inferior performance at high levels of residential heat pump penetration.
\end{abstract}

Keywords: Electricity price, direct load control, heat pump, load shifting, electricity generation, integrated assessment model

\footnotetext{
${ }^{*}$ Corresponding authors

Email addresses: dieter.patteeuw@kuleuven. be
}

Preprint submitted to Applied Energy
(Dieter Patteeuw), lieve.helsen@kuleuven.be (Lieve Helsen)

January 11, 2016 
1 Nomenclature

$2 \mathrm{~A}$

$3 \quad \mathrm{~B}$

${ }_{4} \mathrm{CO}_{2} t_{i, j}$

5 cur $_{j}$

$6 d_{j}^{H P}$

$7 d_{j}^{I M}$

8

9 $d_{j}^{\text {trad }}$

${ }_{10} f c_{i, j}$

${ }_{11} g_{i, j}^{P P}$

$12 g_{j}^{R E S}$

$13 \quad n b$

${ }_{14} p_{s, j}^{A U X}$

${ }_{15} p_{s, j}^{H P}$

$16 \operatorname{price}_{j}^{G}$

17

${ }_{18} \operatorname{price}_{j}^{I}$

19

${ }_{20} q_{s, j}^{D H W}$

${ }_{21} \quad q_{j}^{S}$

$22 \quad q_{s, j}^{S}$

${ }_{23} r c_{i, j}$

${ }_{24} \quad s c_{i, j}$

${ }_{25} t_{j}^{e}$

${ }_{26} \quad t_{j}^{g}$

${ }_{27} t_{s, j}^{\max }$

${ }_{28} t_{s, j}^{\text {min }}$

${ }_{29} t_{s, j}$ file
State space model matrix

State space model matrix

$\mathrm{CO}_{2}$ emission cost

Curtailment of RES

Heat pump electricity demand

Centrally-suggested demand pro-

Traditional electricity demand

Fuel cost

Power plant electricity generation 41

RES electricity generation

Number of buildings

Electricity demand auxiliary

Electricity demand heat pump

Price profile from generation model

Price profile from integrated model

Domestic hot water demand

Solar heat gains

Internal heat gains

Ramping cost

Start-up cost

Ambient air temperature

Ground temperature

Maximum comfort temperature

Minimum comfort temperature

Temperature vector
${ }_{31} z_{i, j}$

$32 \mathrm{HP}$

$33 \quad \mathrm{PP}$

$34 \quad \mathrm{RES}$
36

37

38

39
Weighting factor load shaping

Power plant commitment status

Heat pump

Power plant

Renewable energy sources

\section{Introduction}

Demand response is a form of demand-side management for altering consumers' electrical demand profiles by means of incentives such as dynamic electricity prices [1]. According to Strbac [2], demand response can reduce the need for investments in electricity generation, transmission, and distribution infrastructure, as well as mitigate negative effects associated with the large-scale introduction of generation from intermittent and variable renewable energy sources (RES). Among the multiple methods to attain demand response, as discussed by Gellings [3], this paper focusses on load shifting. In this paper, load shifting is employed to avoid electricity demand at times when power plants with lower efficiency are running and to increase demand at times when renewable energy sources are curtailed. There are various methods to attain load shifting with minimal to no impact on process quality [4, including the process of providing heating or cooling in a building context. Load shifting of heating and cooling demand can either be performed manually by the building occupants or automatically. As shown by Wang et al. [5] and Dupont [6], automatic control achieves higher participation in demand response than manual control. The smart thermostat, an enabling technology to achieve automatic control for heating and cooling demand [7, has drastically increased its market share in recent years 8]. Apart from improving energy efficiency [9], some of these internet-connected smart thermostats already perform peak shaving while maintaining thermal comfort [10]. 
In the literature, one can find two approaches 116 to determining the potential benefits of load 117 shifting, either from a grid perspective or a 118 building owner's perspective. In order to eval- 119 uate the potential benefits of load shifting from 120 an electric system perspective, authors typi- 121 cally consider direct load control [11, 12, 13, 14, 122 15. In this way, applying load shifting to res- 123 idential buildings with heat pumps allows nu- 124 merous benefits, such as balancing short-term 125 power fluctuations of wind turbines [11], pro- 126 viding reserves [12] or voltage stability [13], re- ${ }_{127}$ ducing wind energy curtailment by up to $20 \% 128$ [14, and reducing $\mathrm{CO}_{2}$ emissions by up to $9 \% 129$ [15.

On the other hand, studies conducted from a ${ }^{131}$ building owner's perspective typically consider ${ }^{132}$ a wholesale electricity price profile and assume the actions taken under load shifting do not ${ }^{134}$ effect this price profile. For example, Kamgarpour et al. 16] found that for a set of 1000 residential buildings, savings of up to $14 \%$ can be attained with respect to a wholesale electricity price profile. Henze et al. [17] attained savings up to $20 \%$ by employing the passive energy storage present in an office building with respect to an on-peak and off-peak electricity tariff. Kelly et al. [18, also investigated the use of thermal energy storage to shift electricity demand to off-peak periods, but reported significant increases in energy use. In addition, Kelly et al. observed a loss of load diversity ${ }^{146}$ causing a peak demand during off-peak tariff periods (rebound), which is up to $50 \%$ higher ${ }^{14}$ than normal. This loss of load diversity phenomenon for thermostatically controlled loads is explained well by $\mathrm{Lu}$ and Chassin [19]. More advanced and dynamic price profiles have been suggested in different studies, e.g. Oldewurtel et al. 20] suggest a price profile based on the spot price and on the level of the traditional electricity demand. A good overview of different price based incentives for consumers is provided by Dupont et al. [21.

The motivation for the work presented in this 160 paper revolves around the question what value grid flexibility offers. While there appears to be universal agreement that elasticity in electrical demand will be instrumental in dealing with variable and intermittent RES, little is known regarding the quantitative extent of the benefits resulting from load flexibility vis-a-vis conventional supply side options for accommodating the RES variability. This work begins this valuation of grid flexibility by investigating the optimal control of thermostatically controlled loads of electrically driven heat pumps under a set of simplifying assumptions, which are necessary to solve this approximated problem in human time. Future work will consider other flexible loads including, but not limited to, electric vehicle charging, commercial building thermal mass and HVAC systems control, and dispatchable home appliances.

In this research a unique approach is suggested and evaluated: First, both the electricity generation system and the buildings equipped with heat pumps are modeled and optimized jointly in order to evaluate the theoretically maximum benefits and impact of load shifting, similar to [22, 23]. Modeling both systems also allows studying different load shifting incentives. Both supply and demand systems are assumed to behave rationally and strive to minimize their observed cost. To this aim, all buildings considered feature a model predictive controller (MPC) developing optimal thermostat setpoint strategies. This could be achieved, for example, by a massive deployment of smart thermostats performing MPC. In this context, MPC is a control approach, which optimizes the control of a building's heating and/or cooling system by harnessing a simplified physical model of the building's thermal characteristics and energy systems along with predictions on occupancy and weather conditions. As shown in experiments in tertiary buildings by Širokỳ et al. 24], MPC can reduce energy use up to $28 \%$. Buildings with MPC can easily cope with dynamic price pro- 
files, as shown by Oldewurtel et al. [20].

The aim of this paper is twofold. First, it ${ }^{207}$ is of interest how much operational costs and ${ }^{208}$ $\mathrm{CO}_{2}$ emissions of the electric system can be ${ }^{209}$ reduced by a widespread application of load ${ }^{210}$ shifting for low-energy residential buildings ${ }^{211}$ equipped with electric heat pumps. Hence, this ${ }^{212}$ paper does not consider the potential of load ${ }^{213}$ shifting in alleviating grid congestion, provid- ${ }^{214}$ ing spinning reserves, offering frequency regu- ${ }^{215}$ lation, or providing voltage stability. Instead, ${ }^{216}$ this paper aims at assessing, in a deterministic ${ }^{217}$ manner, how much fossil fuel use and RES cur- ${ }^{218}$ tailment can be avoided at the electric system ${ }^{219}$ level. The main focus of the paper is to com- ${ }^{220}$ pare two common approaches to attain the de- ${ }^{221}$ sired benefits through load shifting with a prac- ${ }^{222}$ tical implementation in mind: direct-load con- ${ }^{223}$ trol and time-of-use pricing. These incentives ${ }^{224}$ are compared by determining to what extent ${ }^{225}$ the reductions in operational costs and $\mathrm{CO}_{2}{ }^{226}$ emissions, as enabled by load shifting, are at- ${ }^{227}$ tained. The results of the first part involving ${ }^{228}$ the joint optimization of energy supply and de- ${ }^{229}$ mand system serve as a reference benchmark ${ }^{230}$ for this comparison.

In this study, the presented models are built 231 on many simplifying assumptions. All models employ perfect predictions and assume the ab- ${ }^{232}$ sence of model mismatch. All buildings possess ${ }^{233}$ ideal model predictive controllers and have an ${ }^{234}$ identical building structure. The heat pumps ${ }^{235}$ have a predetermined, fixed COP for each op- ${ }^{236}$ timization horizon and can modulate perfectly. ${ }^{237}$ There are no constraints and losses of the transmission and distribution grids. Also, there is 238 no import or export of electricity. Finally, ${ }_{239}$ there is perfect competition among all power ${ }_{240}$ plants and buildings.

This paper will show that, even under these 242 strong assumptions and simplified determinis- 243 tic assessment, the performance of the studied 244 load shifting incentives already significantly de- 245 viates from the load shifting performance of the 246 jointly optimized best-case scenario. Addition- 247 ally, it is shown that this performance is very sensitive to the share of RES and the number of participating buildings.

The boundary conditions in this study are inspired by the Belgian context, with an electricity generation system dominated by nuclear power plants, gas-fired power plants, and renewable energy sources (RES). The buildings considered are all detached, heating-dominated low-energy buildings. As shown by Patteeuw et al. [23], low-energy buildings are the best candidates for a widespread heat pump implementation in Belgium. Section 2 describes the different models and scenarios employed in this paper. The Results Section (Section 3) illustrates the output of the different models (Section 3.1) used to evaluate the load shifting potential (Section 3.2) and the performance of load shifting incentives (Section 3.3). The difference between the performance of these load shifting incentives is explained in Section 3.4 while results for mixtures of these incentives are shown in Section 3.5. Finally, a discussion is given in Section 4 in order to arrive at the conclusions in Section 5 .

\section{Methodology}

This section consists of two parts. Section 2.1 elaborates on the different models used, and the case study for assessing the load shifting incentives. Section 2.2 illustrates the different scenarios considered for applying these incentives.

\subsection{Models and parameters}

All models in this article are examined as deterministic optimal control problems as listed in Table 1. In the first model (Gen), the electricity generation system minimizes its total operational cost via a unit commitment and economic dispatch problem with profiles for electricity demand and electricity generation by RES. From a building owners' perspective (B20 and B2), the heat pumps in the buildings 
Table 1: Overview of the abbreviation (Abbr.) and description of the models in this study.

\begin{tabular}{l|l} 
Abbr. & Description \\
\hline \hline Gen & Electricity generation system model \\
\hline B20 & $\begin{array}{l}\text { Large building stock model, optimal } \\
\text { control problem of 20 buildings. }\end{array}$ \\
\hline B2 & $\begin{array}{l}\text { Aggregated building stock model } \\
\text { based on B20. }\end{array}$ \\
\hline Int20 & $\begin{array}{l}\text { Integrated model performing a } \\
\text { co-optimization of B20 and Gen. }\end{array}$ \\
\hline Int2 & $\begin{array}{l}\text { Integrated model performing a } \\
\text { co-optimization of B2 and Gen. }\end{array}$ \\
\hline
\end{tabular}
are controlled by MPC that minimizes individ- 279 ual electricity cost while maintaining thermal 280 comfort. In the integrated models, the two op- 281 timal control problems are combined into one ${ }_{282}$ optimal control problem (Int20 or Int2) that ${ }_{283}$ jointly minimizes the total cost for generating 284 electricity for both the traditional electricity 285 demand and the total electricity demand, in- 286 cluding that stemming from low-energy build- 287 ings with heat pumps whose temperature set- 288 points can be optimized. These models are ${ }_{289}$ mixed integer linear programs (MILP) with ${ }_{290}$ an optimality gap of $0.1 \%$, implemented in 291 GAMS 24.4 and MATLAB 2011b, using the ${ }_{292}$ MATLAB-GAMS coupling as described by ${ }_{293}$ Ferris [25] with CPLEX 12.6 as solver. All pre- ${ }_{294}$ sented results are from a full year simulation ${ }_{295}$ for which the electricity demand and weather ${ }_{296}^{295}$ conditions are based on Belgium in 2013.

Electricity generation system. The electricity 300 generation system is modeled as a unit com- 301 mitment and economic dispatch problem [26]. 302 For every time step $j$, the commitment status 303 (binary variable $z_{i, j}$ ) and the hourly output of 304 each power plant with index $i\left(g_{i, j}\right)$ are deter- 305 mined along with the curtailment of renewable 306 energy sources $\left(\right.$ cur $\left._{j}\right)$ in order to minimize the 307 total operational cost of meeting the electricity 308 demand:

$$
\min \sum_{i, j} f c_{i, j}+c o_{2} t_{i, j}+s c_{i, j}+r c_{i, j}
$$

subject to

$$
\begin{aligned}
& \forall j: d_{j}^{\text {trad }}+n b \cdot d_{j}^{H P}=\operatorname{cur}_{j} \cdot g_{j}^{R E S}+\sum_{i} g_{i, j}^{P P} \\
& \forall j: 0 \leq \operatorname{cur}_{j} \leq 1 \\
& \forall i, j: f\left(g_{i, j}^{P P}, z_{i, j}\right)=0 .
\end{aligned}
$$

The total cost consists of fuel cost $\left(f c_{i, j}\right)$, $\mathrm{CO}_{2}$ emission costs $\left(\mathrm{co}_{2} t_{i, j}\right)$, and costs related to starting $\left(s c_{i, j}\right)$ and ramping $\left(r c_{i, j}\right)$ of power plants. Electricity generation from renewable energy sources $\left(g_{j}^{R E S}\right)$ is assumed to have an operational cost of zero. As described in Appendix A or by Patteeuw et al. [27, the constraints $\left(f\left(g_{j}^{P P}, z_{i, j}\right)\right)$ include minimum and maximum operating points, ramping rates, minimum up and down times and startup costs. The electricity demand consists of two parts. The first is the traditional nationalscale electricity demand, assumed to remain a fixed profile $\left(d_{j}^{\text {trad }}\right)$. The second part is the electricity demand of the heat pumps $\left(d_{\mathrm{j}}^{\mathrm{HP}}\right)$. Given the load diversity due to the difference in user behavior, as discussed in the text below, the electricity demand of the heat pumps is scaled linearly with a factor $n b$ and hence represents the demand of a large portfolio of buildings. In order to study the magnitude sensitivity, the number of buildings is varied in multiple steps between 50,000 and 500,000. Hence, on a yearly basis, the heat pumps of the buildings respectively add an electricity demand between 0.4 and $4 T W h$ to the traditional electricity demand of $85.6 T W h$ [28], i.e. at most roughly $5 \%$.

The technical parameters and fuel costs for the power plants are taken from Bruninx et al. 29] and summarized in Table 2. These technical parameters and costs are inspired by 
Table 2: Parameters for the electricity generation sys- 344 tem per fuel type 29, 30, 28, 31.

\begin{tabular}{l|rrr} 
Type & $\begin{array}{r}\text { Total } \\
\text { cap. } \\
(\mathrm{MW})\end{array}$ & $\begin{array}{r}\text { Nr. of } \\
\text { units } \\
(-)\end{array}$ & $\begin{array}{r}\text { Nominal } \\
\text { cost } \\
\left(\frac{E U R}{M W h_{e}}\right)\end{array}$ \\
\hline \hline Nuclear & 5925 & 8 & 6 \\
Coal & 760 & 3 & 30 \\
Gas & 7018 & 47 & 60 \\
Oil & 215 & 13 & 83 \\
\hline
\end{tabular}

the Belgian power system. However, in order to cope with the large production by RES, the technical parameters for the nuclear power plants are taken from more flexible nuclear power plants than currently present in Belgium. Hence, the generation system is inspired by, but not completely representative for Belgium. Additionally, as mentioned in the beginning of the Methodology section, losses or capacity limits due to the electricity grid are ${ }^{352}$ neglected.

The profile for the traditional electricity de- ${ }^{354}$ mand $\left(d_{j}^{\text {trad }}\right)$ consists of the Belgian electric- ${ }^{355}$ ity demand, from which the electricity genera- ${ }^{356}$ tion by combined heat and power, run-off river, ${ }^{357}$ and pumped hydro are subtracted. The profiles ${ }^{358}$ for these demand and generation types are as- ${ }^{359}$ sumed to be constant and are taken from Elia ${ }^{360}$ [30] for Belgium for the year 2013. Electricity ${ }^{361}$ generation from PV, onshore wind and offshore ${ }^{362}$ wind is lumped together in $g_{j}^{R E S}$ with a share ${ }^{363}$ based on the year 2013 in Belgium 30! $3 \%,{ }^{364}$ $2.2 \%$ and $2.7 \%$, respectively. The generation ${ }^{365}$ profiles of these RES are also for Belgium in the 366 year 2013 [30. In order to study the sensitiv- 367 ity of the results towards the share of electricity 368 generation from RES, the generation profile is 369 scaled up in order to represent $15 \%, 20 \%, 30 \% 370$ and $40 \%$ of the yearly electricity demand, de- 371 pending on the case. According to Devogelaer 372 et al. 32, these are feasible shares for Belgium. ${ }^{373}$

Residences with heat pumps. Regarding the 375 residences with heat pumps, the individual cost 376 minimization is a linear optimal control prob- 377 lem, towards minimizing the total electricity demand $\left(\sum_{j} d_{j}^{H P}\right)$ of multiple buildings, denoted by the index $s$ :

$$
\min \quad \sum_{j} d_{j}^{H P}=\sum_{s}\left(p_{s, j}^{H P}+p_{s, j}^{A U X}\right)
$$

subject to

$$
\begin{aligned}
& \forall s, j: t_{s, j+1}=\mathbf{A} \cdot t_{s, j} \\
& +\mathbf{B} \cdot\left[p_{s, j}^{H P}, p_{s, j}^{A U X}, t_{j}^{e}, t_{j}^{g}, q_{j}^{S}, q_{s, j}^{I}, q_{s, j}^{D H W}\right] \\
& \forall s, j: t_{s, j}^{\min } \leq t_{s, j} \leq t_{s, j}^{\max } .
\end{aligned}
$$

The demand for space heating and domestic hot water (DHW) is either provided by an aircoupled heat pump $\left(p_{s, j}^{H P}\right)$ or by an auxiliary electrical resistance heater $\left(p_{s, j}^{A U X}\right)$. The building structure is a reduced-order model based on Reynders et al. [33] and illustrated in Figure 1. The combination of reduced-order models of heating system and building model shows a RMSE of $5 \%$ per building with respect to a detailed emulator model [34. The vector $t_{s, j}$ denotes the temperatures of this building structure, along with the average temperature of the DHW storage tank. These temperatures are determined by a state-space model (matrices $\mathbf{A}$ and $\mathbf{B}$ ) and subject to disturbances. These disturbances consist of the ambient air temperature $\left(t_{j}^{e}\right)$, ground temperature $\left(t_{j}^{g}\right)$, solar heat gains $\left(q_{j}^{S}\right)$, internal heat gains $\left(q_{s, j}^{I}\right)$ and DHW demand $\left(q_{s, j}^{D H W}\right)$. The indoor air temperatures as well as the temperature of the storage tank for DHW need to stay within the lower $\left(t_{s, j}^{\min }\right)$ and upper $\left(t_{s, j}^{\max }\right)$ bound in order to maintain thermal comfort. An overview of the model equations is given in Appendix A while a detailed description and verification of the model equations is given by Patteeuw and Helsen [34.

In order to keep the problem size for the best case integrated model (Int20) manageable for the MILP solver, the number of buildings, with index $s$ was chosen to be 20. Each of the 20 


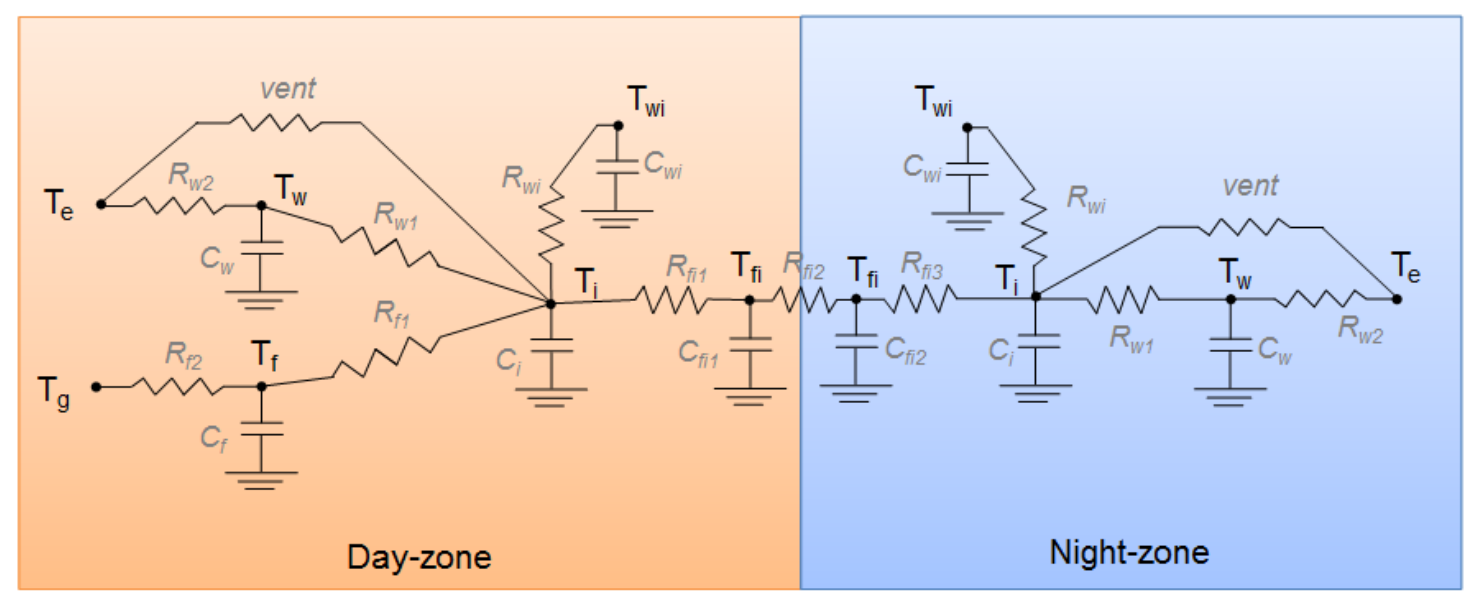

Figure 1: The structure of the reduced order building model as developed by Reynders et al. [33. The day zone consists of 5 states: the temperatures of the indoor air $\left(T_{i}\right)$, internal walls $\left(T_{w i}\right)$, external walls $\left(T_{w}\right)$, ground floor $\left(T_{f}\right)$ and floor connecting the day zone and night zone $\left(T_{f i}\right)$. The night zone also has a state for this connection, along with a temperature for indoor air, internal walls and a lumped state for external walls and roof $\left(T_{w}\right)$. The parameters for the different $\mathrm{R}$ and $\mathrm{C}$ values can be derived based on Protopapadaki et al. [35]. The ambient air temperature $\left(T_{e}\right)$ and ground temperature $\left(T_{g}\right)$ are boundary conditions to the model.

buildings has a different user behavior, based 404 on Baetens and Saelens [36, but an identical 405 building structure. This results in a diversity 406 factor of $75 \%$, similar to the active occupancy 407 of Richardson et al. [37. Hence, the build- 408 ings are assumed to be represented by an av- 409 erage building, as the load shifting potential 410 for thoroughly insulated buildings is very sim- 411 ilar [23. This average building is split up in 412 two thermal zones as proposed by Reynders 413 et al. 33. (see Figure 1). The first zone, 414 named "day zone", consists of the ground floor 415 and includes the rooms where the occupants 416 are active by day. The other rooms, consist- 417 ing mainly of bedrooms, make up the second 418 zone named "night zone". Based on the TABULA 38 project in which representative buildings for the Belgian building stock were investigated, the day and night zone have a floor area of $132 \mathrm{~m}^{2}$ and $138 \mathrm{~m}^{2}$ respectively. Furthermore, this study focuses on low-energy buildings. According to the economic optimum for Belgium [39], these buildings have an average U-value of $0.3 \mathrm{~W} / \mathrm{m}^{2} \mathrm{~K}$ and a ventilation rate of 0.4 air changes per hour (ACH).

Each building is equipped with floor heat- ing and a hot water storage tank for domestic hot water, which are both heated by an air coupled heat pump. The heat pump is sized to meet $80 \%$ of the peak heat demand while the rest of the peak demand is covered by an auxiliary electric resistance heater. The coefficient of performance (COP) of the heat pump is predetermined according to Bettgenhäuser et al. 40 and assumed constant throughout each optimization horizon of a week. The constant COP assumption in optimal control problems has been studied by Verhelst et al. 41 and Patteeuw and Helsen 34. Finally, weather data is based on measurements in Uccle (Brussels, Belgium).

Integrated model. In the integrated model, the two above mentioned optimal control problems are merged into one optimal control problem. The buildings no longer minimize their own electricity use and Eq. (5) becomes a constraint instead of an optimization criterion. Hence, the objective function is the total operational cost minimization of meeting the electricity demand, with the added freedom of shaping the 
heat pumps' electricity demand:

$$
\min \sum_{i, j} f c_{i, j}+c o_{2} t_{i, j}+s c_{i, j}+r c_{i, j}
$$

subject to

$$
\begin{aligned}
& \forall j: d_{j}^{\text {trad }}+n b \cdot d_{j}^{H P}=\operatorname{cur}_{j} \cdot g_{j}^{R E S}+\sum_{i} g_{i,}^{P P} \\
& \forall j: 0 \leq \operatorname{cur}_{j} \leq 1 \\
& \forall i, j: f\left(g_{i, j}^{P P}, z_{i, j}\right)=0 \\
& \forall j: d_{j}^{H P}=\sum_{s}\left(p_{s, j}^{H P}+p_{s, j}^{A U X}\right) \\
& \forall s, j: t_{s, j+1}=\mathbf{A} \cdot t_{s, j} \\
& +\mathbf{B} \cdot\left[p_{s, j}^{H P}, p_{s, j}^{A U X}, t_{j}^{e}, t_{j}^{g}, q_{j}^{S}, q_{s, j}^{I}, q_{s, j}^{D H W}\right] \\
& \forall s, j: t_{s, j}^{\min } \leq t_{s, j} \leq t_{s, j}^{\max } .
\end{aligned}
$$
462 operational benefits of load shifting for the elec- ${ }^{462}$ tricity generation system, as shown in 42. $\quad{ }_{463}$

In the ideal case, this integrated model has ${ }_{464}$ available all details of buildings participating in ${ }_{465}$ load shifting (Int20) ${ }^{1}$. In practice however, the ${ }_{466}$ number of participating buildings could go up ${ }_{467}$ to thousands, making an integrated optimiza- 468 tion infeasibly large. Thus, an aggregation of ${ }_{469}$ this large building set is necessary. Assuming 470 the presented average building to be represen- ${ }_{471}$ tative for a wider set of buildings, an aggrega- 472 tion with respect to building parameters is not ${ }_{473}$

$$
5 \mathrm{~d}
$$$$
\text { fil }
$$
files which still provide thermal comfort (blue lines in Figure 2a and Figure 2b. This is done by performing the minimization towards electricity demand, as given by Eq. (5) to Eq. (7), to determine the lowest possible temperatures for the day zone, night zone and storage tank for DHW, one for each building. In a second step, these temperature profiles are averaged over all buildings considered (black line in Figure 2c). These averaged temperature profiles serve as lower bounds $\left(T_{s, j}^{\text {min }}\right)$ for the aggregated building stock of the integrated model (Int2). In this model, only two buildings remain, with the "average" building structure but with two different sizes of the DHW storage tank.

\footnotetext{
${ }^{1}$ In some cases, the integrated optimization with 475 20 buildings (Int20) was not able to attain a solu- 476 tion. For the other cases, the results were very close ${ }_{477}$ to the integrated model with the aggregated buildings (Int2), more precisely within the optimality gap of $0.1 \%$. Hence, in the failed cases of Int20, the result from Int2 serves as result for Int20.
}

\subsection{Incentive scenarios}

Given the modeling framework discussed in Section 2.1, it is possible to study different incentive mechanisms for realizing the possible operational benefits of load shifting. Figure 3 gives an overview of the different incentive scenarios.

First, in the Reference scenario, no load shifting is performed. In this scenario, the controls of the heat pumps of the 20 buildings (B20) completely ignore the electricity generation system and focus on minimizing their own electricity use. Hence, in this scenario the buildings face a flat electricity price. This results in the following optimization criterion for the optimal control problem of the MPC:

$$
\min \sum_{j} d_{j}^{H P} .
$$




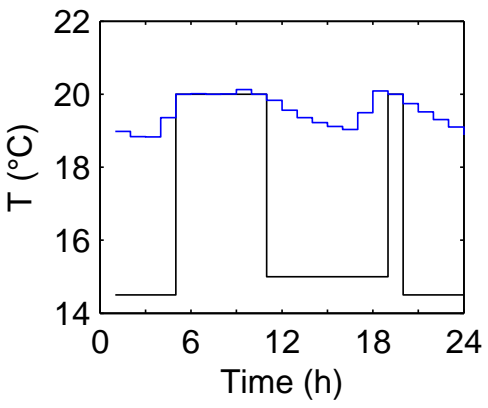

(a) Building 1

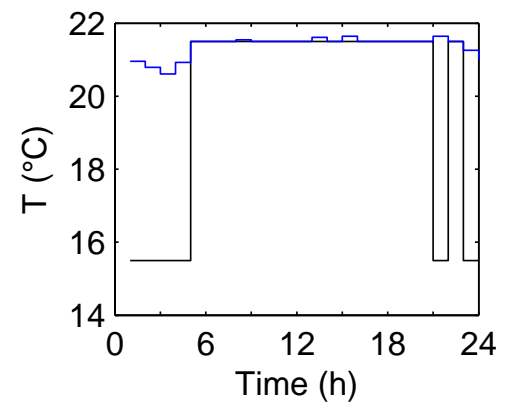

(b) Building 2

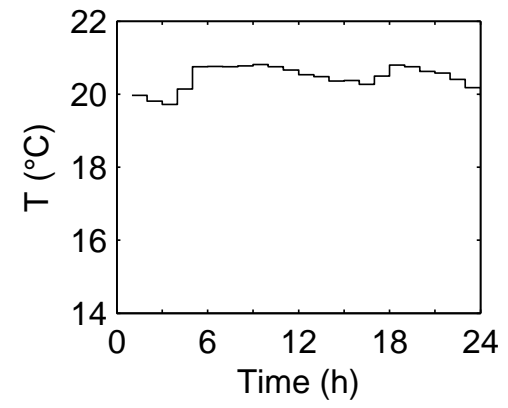

(c) Aggregated

Figure 2: Example of user behavior aggregation for 2 buildings, based on 34. Black lines denote a lower set point for the operative temperature in the day zone. Blue lines denote the actual temperature profiles.

From this, the electricity generation system 506 (Gen) needs to deliver this resulting heat pump 507 electricity demand plus the traditional electric- 508 ity demand.

In the Best Case scenario, the electricity gen- 510 eration system and all participating buildings 511 simultaneously optimize their control by means 512 of an integrated model (Int20). In this model, 513 the building structure and domestic hot water 514 tanks are occasionally preheated when this re- 515 duces the total cost for the electricity genera- 516 tion system. Simultaneously, the power plants 517 are optimally dispatched in order to meet the 518 resulting electricity demand. This Best Case 519 scenario serves as upper bound of the opera- 520 tional cost savings attainable by applying load 521 shifting.

A first time-of-use pricing scenario is the ${ }^{523}$ Price G scenario. In this scenario, the electricity generation system makes an estimate of the total electricity demand of the following day, including the electricity demand of the heat ${ }_{524}$ pumps, which minimize their own consump- ${ }_{525}$ tion. This estimate is assumed to be perfect in ${ }_{526}$ this paper. However, the heat pump controllers ${ }_{527}$ receive the resulting price profile, price $_{j}^{G}$, and ${ }_{528}^{527}$ alter the electricity demand accordingly by ap- ${ }_{529}$ plying the following optimization criterion:

$$
\min \sum_{j} \operatorname{price}_{j}^{G} \cdot d_{j}^{H P}
$$

In real-time, the electricity generation faces the traditional electricity demand plus the altered building electricity demand. This scenario hence represents a unilateral price communication from the electric power system to the buildings with heat pumps.

In contrast to this, the Price I scenario represents the situation where the electricity generation system makes an estimate of the flexibility of the buildings with heat pumps. In the estimate for the following day, the aggregated representation of the buildings with heat pumps (B2) is co-optimized with the dispatch of the electricity generation system. The resulting price profile from this integrated model, price $_{j}^{I}$, is then communicated to the controllers of the heat pumps, resulting in the following optimization criterion

$$
\min \sum_{j} \operatorname{price}_{j}^{I} \cdot d_{j}^{H P} .
$$

Also in this scenario, the impact of the measure on the electricity generation system is determined.

Finally, the Load Shaping scenario is identical to the Price I scenario except that, instead of communicating the resulting price profile, the resulting demand profile from the integrated model $\left(d_{j}^{I M}\right)$ is communicated to the buildings. This demand profile, similarly to the work of Corbin and Henze [43, 44], acts 


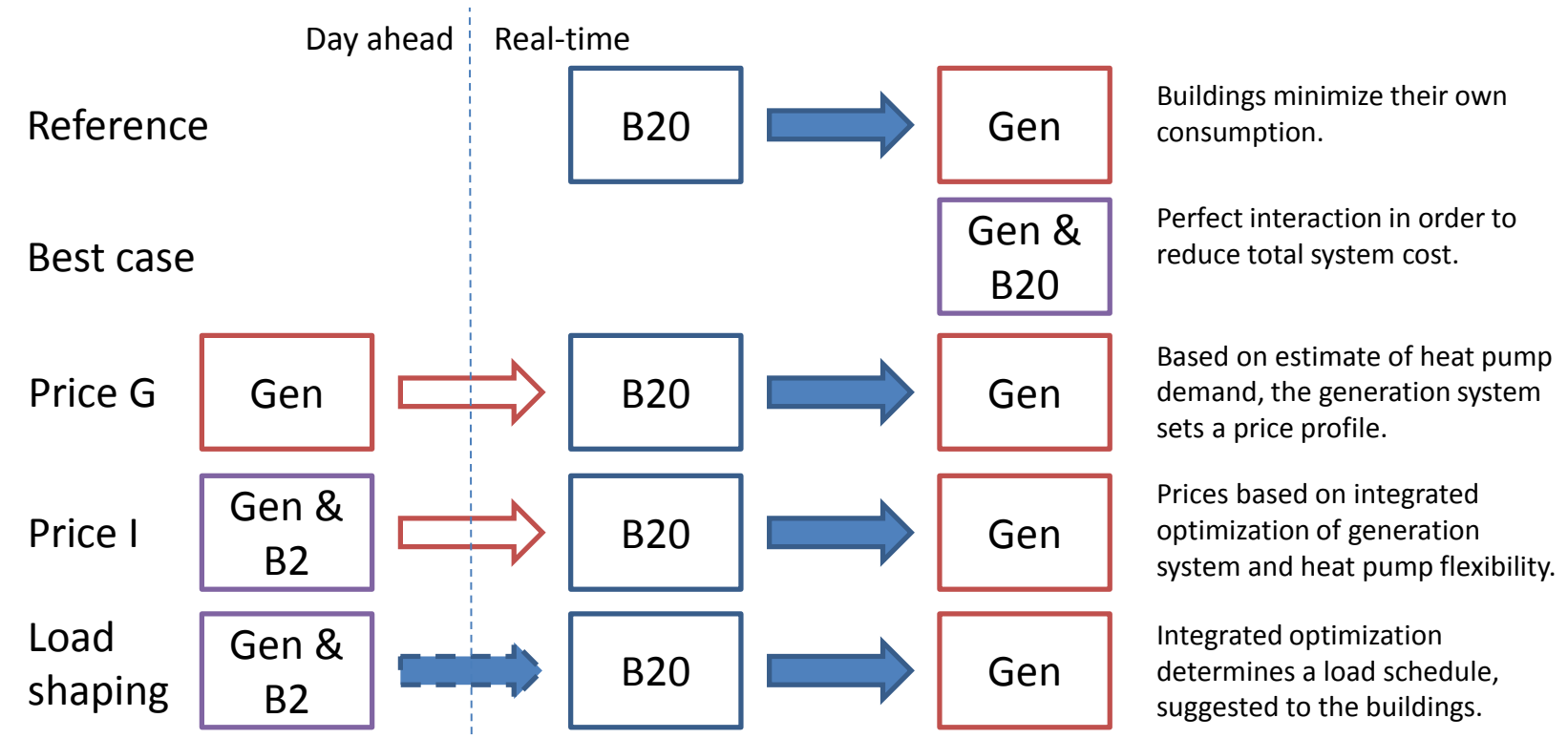

Figure 3: An overview of the studied scenario's. The red non-filled arrows denote the communication of a price profile. The blue filled arrows denote the communication of the electricity demand profile of the buildings equipped with a heat pump. In the load shaping scenario, the dashed blue arrow denotes the suggestion of an electricity demand profile. The color of the boxes denotes the model type. The red box denotes the electricity generation system model, the blue box the building stock model and the purple box the integrated model of both.

as a centrally-suggested demand curve for the 551 buildings with heat pumps. The resulting opti- 552 mization criterion for the optimal control prob- 553 lem of the heat pump controllers is:

$$
\min w \cdot\left|d_{j}^{H P}-d_{j}^{I M}\right|+(1-w) \cdot \sum_{j} d_{j}^{H P} \quad(18)^{557}
$$

in which $d_{j}^{I M}$ represents the centrally- ${ }^{558}$ suggested demand profile from the integrated 559 model. Hence, the heat pump controllers 560 make a trade-off between the deviation with re- 561 spect to the centrally-suggested demand profile 562 $\left(\left|d_{j}^{H P}-d_{j}^{I M}\right|\right)$ and minimizing electricity use 563 $\left(\sum_{j} d_{j}^{H P}\right)$ by means of the weighting factor $w, 564$ taken to be 0.5 in this study.

\section{Results}

The Results Section consists of five parts. 569 In the first part, Section 3.1, the output of 570 the different models, presented in Table 1, is 571 illustrated. In Section 3.2, the potential of 572 load shifting is investigated for the studied boundary conditions. The results for the different load shifting implementation scenarios are shown in Section 3.3 and the resulting metrics in Section 3.4. Finally, the different cost functions for the buildings, Eq. (15) to (18), are combined in Section 3.5 .

\subsection{Illustration of model output}

Figure 4 shows the results for two days in the case where $30 \%$ of the yearly electricity demand is generated from RES and 250,000 buildings are equipped with heat pumps. The power plants need to generate the sum of the residual traditional electricity demand, Figure 4a, and the electricity demand of the heat pumps, Figure 4c. Note that, in some scenarios, both the heat pump and auxiliary heater are activated simultaneously, causing a high electricity demand of $10 k W_{e}$ per building. Figure $4 \mathrm{~b}$ shows how the day zone temperatures, averaged over the buildings, are manipulated to achieve these electricity demands. In the 


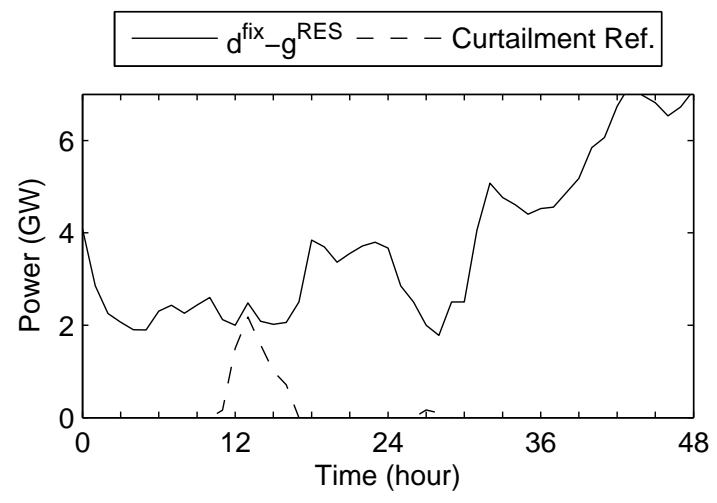

(a) Electric power

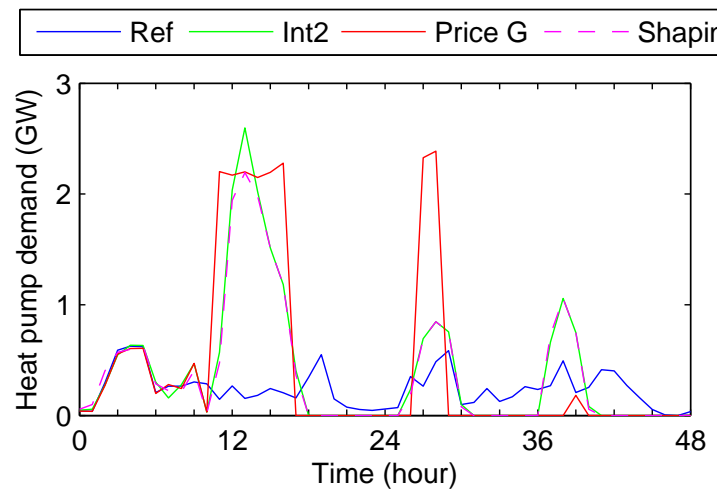

(c) Electric power

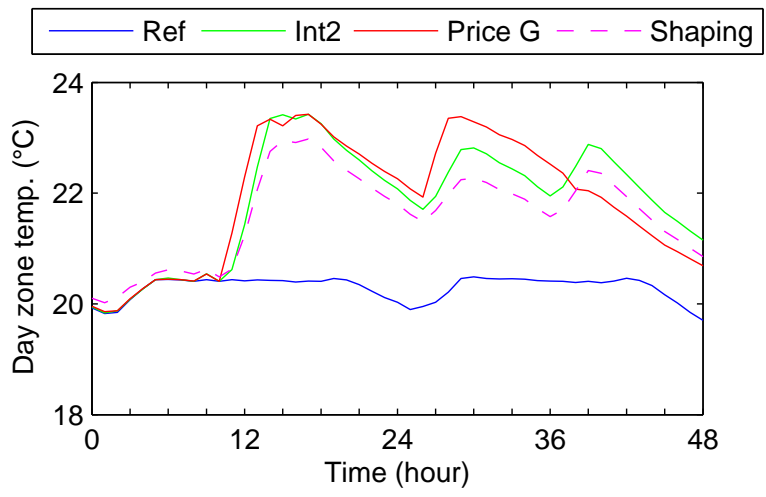

(b) Temperature

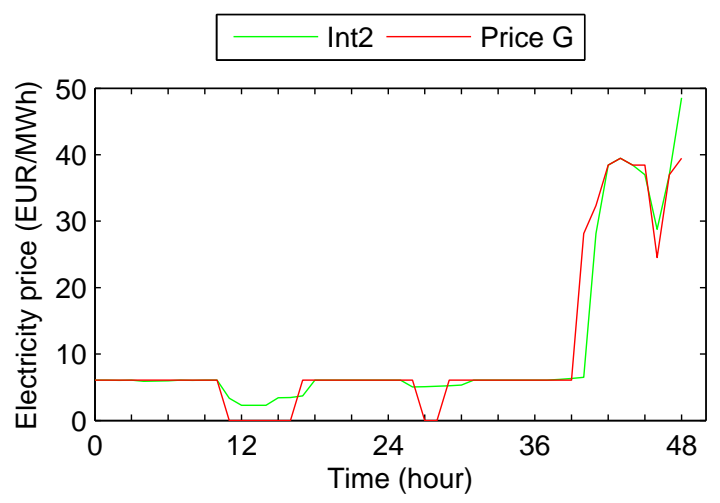

(d) Price

Figure 4: The power plants must deliver the sum of the traditional residual demand (Figure 4a) and the heat pumps demand (Figure 4c). The curtailment at hours 11 to 16 and hours 27 to 28 , in some cases communicated through a price profile (Figure 4d, forms an incentive to preheat the buildings (Figure 4b).

Reference scenario (blue lines in Figure 4), the 588 indoor air temperatures are kept close to the 589 lower comfort bounds, resulting in an elec- 590 tricity demand that doesn't strongly fluctuate. 591 In this scenario, the buildings miss the op- 592 portunity of using the excess electricity gen- ${ }_{593}$ eration by RES that gets curtailed in hours 594 11 to 16 and hours 27 to 28 . In the Best ${ }_{595}$ Case scenario (green lines in Figure 4) ad- 596 vantage of this abundant electricity genera- 597 tion by RES is taken by drastically increasing 598 heat pump electricity demand $\left(d_{j}^{H P}\right)$ in those ${ }_{599}$ hours. As a result, no electricity generation by 600 RES is curtailed, as the buildings have perfect ${ }_{601}$ knowledge of the magnitude of the curtailment. 602
This avoiding of curtailment causes the nuclear power plants to set the price (green line in Figure 4d and, hence, no zero electricity price is observed.

This is not the case for the Price G scenario (red lines in Figure 4). In this scenario, the buildings face a zero electricity price at times of curtailment, see Figure 4d. This causes the so-called avalanche effect 45 to occur, meaning that the buildings drastically increase their electricity demand as they observe electricity to be completely for free at that time. However, this leads to an overshoot in demand, which will cause the electricity price to go up again in hours 11, 15, 16, 27 and 28. Clearly, this 
will increase the electricity generation cost far 641 more than expected. The Load Shaping sce- 642 nario (pink dashed lines in Figure 4) does not 643 cause this overshoot in demand, as it receives 644 information on how much to increase electric- 645 ity use in these time periods. As can be seen 646 in the figure, the electricity demand profile in 647 the Load Shaping scenario is very close to that 648 of the Best Case scenario.

\subsection{Potential of load shifting}

In this section, the savings in operational cost and $\mathrm{CO}_{2}$ emission of the Best Case scenario for load shifting are shown. This will ${ }^{65}$ serve as an upper bound to the possible savings ${ }^{654}$ of the different load shifting implementation 655 scenarios in Section 3.3. Throughout this pa- 656 per, the results are given for a variation of two ${ }^{657}$ important parameters: The number of build- ${ }^{658}$ ings equipped with heat pumps and the share ${ }^{659}$ of electricity generated by RES over a year. Ta- ${ }^{660}$ ble 3 gives an overview of the total yearly oper- ${ }^{661}$ ational cost and $\mathrm{CO}_{2}$ emissions. Note that the ${ }^{662}$ mentioned number of buildings switch from fos- ${ }^{66}$ sil fuel fired heat production to heat pumps. A ${ }^{664}$ higher number of buildings making this switch, ${ }^{665}$ causes a higher electricity demand and thus ${ }^{666}$ higher operational costs and $\mathrm{CO}_{2}$ emissions for ${ }^{667}$ the electricity generation system $2, \quad 668$

As can be seen in Table 3 , performing load shifting causes operational costs and $\mathrm{CO}_{2}$ emis- ${ }^{670}$ sions to decrease. The trend is however not ${ }^{671}$ linear, as can be seen in the savings per par- ${ }^{672}$ ticipant. This is discussed further by Arte- ${ }^{673}$ coni et al. [46]. A number of buildings higher ${ }^{674}$ than 500,000 is not studied as the peak in to- ${ }^{675}$ tal demand approaches the maximum installed ${ }^{676}$ capacity of the assumed electricity generation ${ }^{677}$ system. A number of buildings lower than ${ }^{678}$

${ }^{2}$ When considering the entire system from a primary 681 energy perspective, buildings and electricity generation 682 system, the switch to heat pumps causes total operational costs and $\mathrm{CO}_{2}$ emissions to lower, see Patteeuw ${ }^{683}$ et al. 23]. This paper only discusses the effects for the 684 electricity generation system.
50,000 is also not studied as for these small numbers, the operational cost savings approach the optimality gap of $0.1 \%$ used in this study.

Another important parameter is the share of electricity generated by RES over a year. As can be seen in Table 3, a higher share of RES causes the potential operational cost savings of load shifting to increase. For example, an increase in RES share from 8 to $40 \%$, causes the potential operational cost savings to rise from 12 million EUR to 28 million EUR.

\subsection{Comparison of incentives scenarios}

The savings presented in Section 3.2 could be hard to attain in practice as the Best Case scenario is not feasible for a large set of buildings. Instead, a set of alternative scenarios for attaining these savings were introduced in Section 2.2. The performance of these different scenarios in striving towards the operational cost savings of the Best Case scenario is shown with respect to the RES share in Figure 5 a for 250,000 buildings with heat pumps. In this figure, $100 \%$ represents the Best Case scenario, while $0 \%$ represents the Reference scenario. Most notable is the poor performance of the Price G scenario. Up to a RES share of $20 \%$, this implementation causes the total operational cost to be even higher than the Reference scenario. This is because the buildings greedily overreact to price incentives and induce extra operational costs for the electricity generation system. Only when the RES share is high enough, does the Price G scenario start showing operational costs reductions with respect to the Reference scenario. However, this increase in savings for a higher RES share is a general trend in all scenarios.

The price signal from the integrated model, scenario Price I, partly avoids the overreaction as it has information on both electricity generation system and buildings. In a sense, it represents the price signal after a long iteration of price and demand between electricity generation system and buildings. However, the Price I scenario is still outperformed by about $20 \%$ 
Table 3: The difference between the Reference and Best Case yields the upper limit for savings by applying load shifting. Both the relative savings and the savings per participant (part.) are shown.

\begin{tabular}{l|rrrrr|rrrrr} 
RES share (\%) & \multicolumn{5}{|c|}{30} & 8 & 15 & 20 & 30 & 40 \\
No. of buildings (x1000) & 50 & 100 & 250 & 375 & 500 & & & 250 & & \\
\hline \hline Reference: cost $\left(10^{6}\right.$ EUR) & 670 & 682 & 723 & 760 & 799 & 1276 & 1048 & 916 & 723 & 595 \\
Reference: $\mathrm{CO}_{2}\left(10^{6}\right.$ ton) & 4.68 & 4.81 & 5.21 & 5.57 & 5.92 & 10.98 & 8.72 & 7.31 & 5.21 & 3.95 \\
\hline Best case: cost $\left(10^{6}\right.$ EUR) & 663 & 670 & 697 & 724 & 755 & 1264 & 1032 & 896 & 697 & 567 \\
Best case: $\mathrm{CO}_{2}\left(10^{6}\right.$ ton) & 4.61 & 4.69 & 4.97 & 5.24 & 5.52 & 10.94 & 8.64 & 7.16 & 4.97 & 3.69 \\
\hline Cost saving (\%) & 1.0 & 1.7 & 3.6 & 4.7 & 5.5 & 0.9 & 1.5 & 2.2 & 3.6 & 4.7 \\
$\mathrm{CO}_{2}$ reduction (\%) & 1.5 & 2.5 & 4.6 & 5.9 & 6.7 & 0.4 & 0.9 & 2.1 & 4.6 & 6.6 \\
\hline Cost saving (EUR/part.) & 140 & 120 & 104 & 96 & 88 & 48 & 104 & 80 & 104 & 112 \\
$\mathrm{CO}_{2}$ reduction (ton/part.) & 1.4 & 1.2 & 0.96 & 0.88 & 0.80 & 0.16 & 0.32 & 0.64 & 0.96 & 1.04 \\
\hline
\end{tabular}

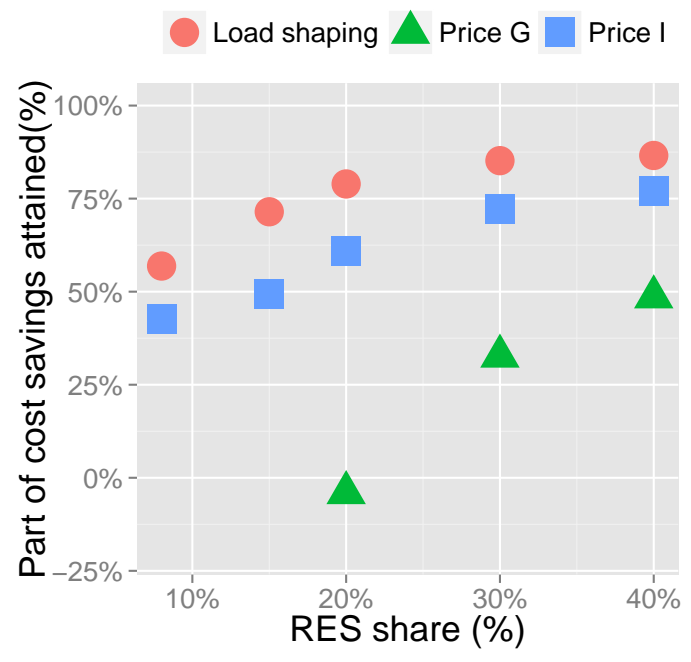

(a) For 250,000 buildings

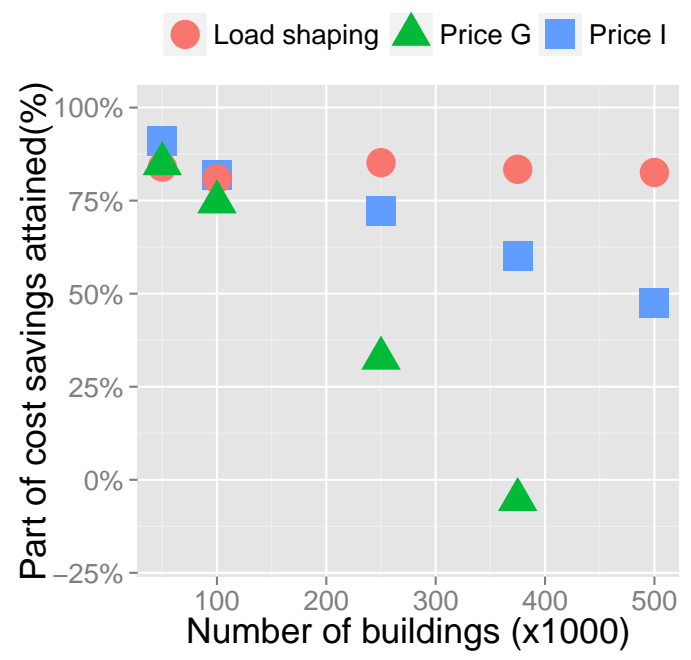

(b) For a $30 \%$ RES share

Figure 5: Scenario comparison for operational cost savings relative to the Best Case scenario of load shifting. In Figure $5 \mathrm{a}$ the share of RES is varied while 250,000 buildings are considered. In Figure 5b the number of participating buildings is varied while the RES share remains at $30 \%$. 
Table 4: The difference in operational cost savings between the different incentive scenarios can be explained by the difference in curtailment of electricity generation by RES (Curt.), the average part load of all operating power plants throughout the year (\%), the difference in fuel and $\mathrm{CO}_{2}$ cost (Fuel $\left.+\mathrm{CO}_{2}\right)$ and the difference in costs related to starting up and ramping of power plants (Start-up + ramping).

\begin{tabular}{|c|c|c|c|c|c|c|c|c|}
\hline \multirow[b]{2}{*}{ Scenario } & \multicolumn{4}{|c|}{$8 \%$ RES } & \multicolumn{4}{|c|}{$40 \% \mathrm{RES}$} \\
\hline & $\begin{array}{l}\text { Curt. } \\
\text { (TWh) }\end{array}$ & $\begin{array}{l}\text { Part } \\
\text { load } \\
(\%)\end{array}$ & $\begin{array}{l}\text { Fuel }+ \\
\mathrm{CO}_{2} \\
(\text { cost i }\end{array}$ & $\begin{array}{c}\text { Start-up + } \\
\text { ramping } \\
10^{6} \text { EUR) }\end{array}$ & $\begin{array}{l}\text { Curt. } \\
\text { (TWh) }\end{array}$ & $\begin{array}{l}\text { Part } \\
\text { load } \\
(\%)\end{array}$ & $\begin{array}{l}\text { Fuel }+ \\
\mathrm{CO}_{2} \\
\text { (cost in }\end{array}$ & $\begin{array}{c}\text { Start-up }+ \\
\text { ramping } \\
10^{6} \text { EUR) }\end{array}$ \\
\hline Reference & 0 & 95.8 & 1252 & 24 & 2.27 & 88.3 & 562 & 33 \\
\hline Best Case & 0 & 97.8 & 1244 & 20 & 1.12 & 88.8 & 538 & 30 \\
\hline Price I & 0 & 96.0 & 1249 & 22 & 1.80 & 88.2 & 544 & 30 \\
\hline Load Shaping & 0 & 97.1 & 1249 & 20 & 1.64 & 87.8 & 542 & 30 \\
\hline
\end{tabular}

by the Load Shaping scenario, although the dif- 718 ference decreases for a higher RES share. $\quad 719$

The difference between Price I and Load 720 Shaping scenarios can be explained using Ta- 721 ble 4. For a low RES share (8\%), there is no 722 curtailment in the electricity generation sys- 723 tem and the operational cost savings by load ${ }_{724}$ shifting (Best Case) are dominated by improv- ${ }_{725}$ ing the efficiency of the power plants (Fuel and ${ }_{726}$ $\mathrm{CO}_{2}$ cost) and avoiding start-up and ramping ${ }_{727}$ costs. The efficiency of the power plants is im- ${ }_{728}$ proved by running these power plants closer to ${ }_{729}$ their full load capacity (see Part load in Table ${ }_{730}$ 4). These savings can be subtle to attain, as a ${ }_{731}$ slight increase in demand above the maximum ${ }_{732}$ generation capacity of the last power plant can ${ }_{733}$ trigger an extra power plant to be activated. ${ }_{734}$ Since in the Load Shaping scenario an exact 735 indication of what the ideal electricity demand 736 profile looks like is given, these subtleties are ${ }_{737}$ better retained. A price profile can give an in- 738 dication of when electricity demand should be 739 increased or decreased, but not how much this ${ }_{740}$ increase or decrease should be.

On the other hand, for a high RES share 742 (40\%), the savings are dominated by reducing 743 RES curtailment in order to decrease opera- 744 tional costs. Both Price I and Load Shaping 745 scenarios are successful in decreasing RES cur- 746 tailment. In the former, the buildings see a 747 very low electricity price and act accordingly. 748 In the latter, the buildings receive information 749 on how much the demand should be increased when curtailment occurs. However, the Load Shaping scenario is better as it communicates how much the demand should be increased in order to exactly absorb all curtailment. This information is not present in a price profile.

The number of buildings having a heat pump installed, also has an impact on the performance of the incentive scenarios as shown in Figure 5b. In this figure, the share of RES in the yearly electricity generation is fixed to $30 \%$. First of all, the Price G scenario performs very poorly as more people install a heat pump that participates in load shifting. In the case of 500,000 buildings, the demand overshoot in the coldest week is so high that the maximum cumulative capacity of the production park is exceeded. With respect to the Price I scenario, when a relatively low number of buildings is involved, this scenario performs the best. However, as more buildings are involved, these all respond to the same price profile, and cause demand overshoots. In this case, the buildings start influencing the price itself, and become price influencers instead of price takers. In the case of 500,000 buildings with heat pumps, the performance is so abysmal that only about half of the potential savings are attained. In contrast to this, the Load Shaping scenario is far more robust to the number of buildings: No matter what this number of buildings is, the Load Shaping scenario attains about $80 \%$ of 
the possible savings.

\subsection{Comparison on metrics}

Similar to the work of Corbin [47, Table 5 presents different metrics to evaluate the improvement of the different incentive scenarios with respect to the Reference scenario. In contrast to the work of Corbin, the full electricity generation system is modeled, which allows a direct interpretation of the residual demand curve. This is the total demand from which the electricity generation from RES is subtracted $\left(d_{j}^{\text {trad }}+n b \cdot d_{j}^{H P}-c u r_{j} \cdot g_{j}^{R E S}\right)$. In all load shifting scenarios, the electricity use of the heat 794 pumps rises by between $13 \%$ to $20 \%$. This is 795 due to the high share of electricity generated by 796 RES and nuclear power plants, which causes a 797 lot of curtailment to occur in the Reference sce- 798 nario. In the model, curtailment is deemed as 799 for free and drastic increases in electricity use 800 occur during these hours. This reduces electric- 801 ity use after the time periods when curtailment 802 occurred. Additionally, for the Best Case, an 803 arbitrary choice between heat pump and auxil- 804 iary heater occurs at times of curtailment, since 805 during these times electricity is observed as for 806 free. The Load Shaping scenario, as shown in 807 Eq. (18), partly minimizes own electricity use, and will mostly choose for the heat pump dur- 808 ing times of curtailment. For the Price G sce- 809 nario, the zero electricity price at curtailment 810 causes a drastic increase in electricity use. The 811 Price I scenario rarely observes this zero elec- 812 tricity price, as illustrated in Figure $4 \mathrm{~d}$, and 813 hence increases electricity use far less.

The peak demand shows interesting differ- 815 ences between the different scenarios. During 816 peak moments, expensive generation plants are 817 running and the Best Case scenario will try 818 to reduce electricity use during these hours as 819 much as possible. The Price I and Load Shap- 820 ing scenarios are able to partially imitate this 821 behavior. However, for the Price G scenario 822 the situation becomes worse than the Refer- 823 ence scenario, as an overreaction to high prices 824
Table 6: Hybrid incentive scenarios in which the optimization criteria are a mixture of minimizing energy use (Energy), minimizing cost with respect to a price profile from the generation (Price G) or the integrated model (Price I) and deviation towards a load profile (Load). The presented attained percentage of operational cost savings is for the case of a $30 \%$ RES share and 250,000 buildings with heat pump.

\begin{tabular}{l|r} 
Name & \% savings \\
\hline \hline Energy+Price G & 38 \\
Energy+Price I & 41 \\
Price I+Load & 90 \\
Energy+Price I+Load & 93 \\
\hline
\end{tabular}

in some hours causes an even higher peak in the hours before.

The mean ramping, calculated as the mean of the absolute value of the ramping from hour to hour, shows significant differences between the scenarios. The Best Case scenario is able to significantly decrease the hour to hour variations in residual demand. The Price I and Load Shaping scenario approximate this behavior while the Price G scenario again shows worse behavior than the Reference case. This is mainly due to the drastic ramping of the heat pump electricity demand right before and after hours of curtailment, as shown in Figure 4c.

\subsection{Hybrid incentive scenarios}

Multiple combinations of the above mentioned scenarios are possible by combining the optimization criteria from Eq. 15 to Eq. 18 . The performance of a selection of these hybrid scenarios are summarized in Table 6 .

Regarding the price-based scenarios, the addition of minimizing total energy use could counteract the overshoot with respect to the price profile. For the Price G scenario, the addition of minimizing energy use in the optimization criterion (Energy+Price G) slightly improves the attained savings from $32 \%$ to $38 \%$. However, for the Price I scenario, adding the minimization of energy use in the optimization criterion (Energy+Price I) drastically decreases the attained savings from $72 \%$ to $41 \%$. 
Table 5: Metrics of the residual load curve $\left(d_{j}^{\text {trad }}+n b \cdot d_{j}^{H P}-c u r_{j} \cdot g_{j}^{R E S}\right)$, similar to Corbin 47, for the case of a $30 \%$ RES share and 250,000 buildings with heat pumps.

\begin{tabular}{l|rrrrr} 
Name & Reference & Best case & Price G & Price I & Load Shaping \\
\hline \hline Heat pump electricity use (TWh) & 1.99 & 2.41 & 2.39 & 2.27 & 2.32 \\
Peak (GW) & 12.6 & 11.9 & 12.8 & 12.3 & 12.0 \\
Mean ramping (MW/h) & 452 & 367 & 502 & 429 & 378 \\
\hline
\end{tabular}

In this combined case, the price profile triggers 861 the correct behavior far less.

In practice, the Load Shaping scenario may 863 be difficult to implement as compensating the 864 participating building owners is not straight- 865 forward. By combining this scenario with 866 a fluctuating price profile, this compensation 867 could be easier. The combination of the price 868 from the integrated model with the load shap- 869 ing (Price I+Load) attains a slightly higher 870 percentage of the operational cost savings 871 (90\%) than the load shaping scenario (85\%). 872 However, this cost function proved to be diffi- 873 cult to handle for the buildings, as in some days it drives the temperature close to its bounds in order to attain more drastic electricity de- ${ }^{875}$ mand profiles. These issues were not observed ${ }^{876}$ in the combination of the three scenarios (En- ${ }^{877}$ ergy+Price I+Load). This final hybrid sce- ${ }^{878}$ nario performs very well in terms of operational ${ }^{879}$ cost savings and attains $93 \%$ of the maximal ${ }_{881}^{880}$ possible operational cost savings.

\section{Discussion}

Load shifting applied to building portfo- ${ }^{885}$ lios with electrically driven heat pumps pro- ${ }^{886}$ vides value for the electricity generation sys- ${ }^{887}$ tem, as it can contribute to lowering system ${ }^{888}$ operational costs and $\mathrm{CO}_{2}$ emissions (Table 3). ${ }^{889}$ For a low number of buildings or a low RES ${ }^{890}$ share, these savings are about $1 \%$ and hence ${ }^{891}$ rather limited. As the number of buildings or ${ }^{892}$ RES share increases, the reductions in oper- ${ }^{893}$ ational cost and $\mathrm{CO}_{2}$ emissions go up to $5 \%{ }^{894}$ and $6.5 \%$ respectively. This is not a drastic ${ }^{895}$ change, but is nonetheless a significant contri- 896 bution. For these cases, the cost savings are 897 typically around 100 EUR per participant per year. Given the typical investment cost of enabling technologies such as the smart thermostat [8] or smart controllers [14] between 200 EUR and 350 EUR, the pay-back period is on the order of magnitude of a few years, for the boundary conditions employed in this study and assuming that all cost savings are directly attributed to the building owners. The order of magnitude of the annual reduction in $\mathrm{CO}_{2}$ emissions is around 1 ton per participant but highly depends on the number of participating buildings and the RES share.

Regarding the magnitude of the operational cost savings of load shifting, Hedegaard and Münster [48] investigated the value of flexible operation of heat pumps in 716,000 buildings for an electricity generation system with a $60 \%$ share of wind generation and biomass fired combined heat and power plants. According to Hedegaard and Münster [48, this flexible operation results in an annual cost saving per participant of 30 EUR due to avoided operational costs and a $2 \%$ reduction in $\mathrm{CO}_{2}$ emissions. When comparing these results with Table 3, the savings are on the same order of magnitude, but are not close. Given the similar climate, building and heat pump characteristics in both studies, the differences in savings are dominated by the composition of the electricity generation system. This difference, along with the large spread of results in Table 3. illustrates that the reductions in operational cost and $\mathrm{CO}_{2}$ emissions are highly case dependent.

Figure $4 \mathrm{c}$ illustrates the avalanche effect as discussed by Dallinger and Wietschel [45] for 
the Price G scenario: all heat pump controllers 943 simultaneously observe a low electricity price 944 and drastically increase demand in those mo- 945 ments. Kelly et al. [18] also observed this over- 946 consumption due to low prices, along with a 947 loss of load diversity. As shown by Ling and 948 Chassin [19, this loss of load diversity can 949 cause simultaneous oscillations in electricity 950 demand of thermostatically controlled loads, 951 causing problems for the electricity generation 952 system following the low price period. As pro- 953 posed by Dallinger and Wietschel [45], when 954 all participants make individual price forecasts, 955 the peak electricity demand is less concentrated 956 and also the load diversity is better preserved. 957

The Load Shaping scenario suffers far less ${ }^{958}$ from the above mentioned effects. First, dur- ${ }^{959}$ ing the moments of curtailment, the buildings ${ }^{960}$ do not receive a low electricity price but in- ${ }^{961}$ formation to increase demand and, equally im- ${ }^{962}$ portant, up to which level to increase demand. In the hour 27 in Figure 4 a for example, there is little curtailment of RES and the buildings know that only a limited increase of electricity demand is necessary. This is far more information than a price signal can hold. Second, 968 the optimization criterion of the Load Shap- 969 ing scenario, Eq. 18, shows that the centrally- 970 suggested demand curve $\left(d_{j}^{I M}\right)$ is merely a sug- 971 gestion, not an obligation, towards increasing 972 or decreasing electricity demand. Part of the 973 optimization criterion is still the electricity use 974 minimization of each individual building. This 975 partly ensures the preservation of load diver- 976 sity, as each building will make an individual 977 trade-off. Nonetheless, preservation of load di- 978 versity could be improved even more by provid- 979 ing each building with a certain perturbation 980 on the centrally-suggested demand curve [45].

The results for the different scenarios (Figure 982 5) show the potential benefit of applying the 983 integrated optimization during the day ahead 984 stage and distributing profiles from this source. 985 The resulting price profile (Price I scenario) 986 clearly outperforms the case where the price 987 profile is unilaterally determined from the electricity generation system (Price G scenario). The Price I scenario can be regarded as the case where the electricity price is infinitely iterated between electricity generation system and the individual buildings. As Figure 5b shows, this price profile causes the system to attain a great amount of the theoretically possible savings, as long as the number of participating buildings remains small. In this sense the buildings are price takers up to this point, and will only have a minor effect on the price itself. As the number of participating buildings increases, this influence will no longer be negligible and the buildings become price influencers. In this sense, the approach of suggesting a load profile instead of a price profile (the Load Shaping scenario) is generally better for a high number of participating buildings, over 100,000 in this study. The relative operational cost savings remain stable in this scenario, even for 500, 000 participating buildings. On a total of 4.6 million households in Belgium [49], this is still a relatively small amount of participating buildings.

From the presented results, one should carefully consider whether time-of-use pricing is the correct way to achieve load shifting. In regions where a high share of the buildings employ electricity for either heating or cooling, a price profile can lead to unintended adverse effects. With the increasing share of smart thermostats 8, which are technically able to act upon such price profiles, these artifacts of greedy control actions could occur shortly afterwards. In these regions, a central determination of a load profile for all buildings to follow, appears to be a better option.

The paper only investigates the effects of different load shifting incentives for low-energy buildings. Patteeuw et al. [23] showed that buildings lacking proper insulation are not suitable candidates for heat pumps, at least not in a Belgian context. Hence, these buildings were not included in this paper. 
With respect to compensation for the build- 1032 ing owner, either a yearly fee or a tempered ${ }_{1033}$ price profile is possible. A yearly compensation can be based on the operational cost savings ${ }^{1034}$ as presented in Table 3 , although it can be $a^{1035}$ challenge to determine which party is responsi- ${ }^{1036}$ ble for paying this compensation. A tempered ${ }^{1037}$ price profile can be used in a hybrid scenario, ${ }_{103}$ such as in the Energy+Price I+Load scenario, ${ }^{1039}$ to automatically compensate the building own- ${ }^{1040}$ ers.

For implementing the Load Shaping scenario ${ }^{1042}$ in practice, the procedure can be followed as ${ }^{1043}$ shown in Figure 3. A day ahead integrated ${ }^{1044}$ optimization of the electricity generation sys- 1045 tem along with an aggregated representation 1046 of the building stock could be performed. The 1047 resulting load profile is communicated to the 1048 generation system operators to determine their 1049 dispatch. Furthermore, the centrally-suggested 1050 demand curve $\left(d_{j}^{I M}\right)$ is communicated to the 1051 smart thermostats of all participating build- 1052 ings, with a small perturbation applied in order 1053 to maintain load diversity. The electricity gen- 1054 eration system thus runs business as usual, al- 1055 beit in providing an altered electricity demand profile.

\section{Conclusion}

In this paper, results are presented of mod- ${ }^{1060}$ eling two perspectives on load shifting for heat ${ }^{1061}$ pumps. The first perspective is the classical ${ }^{1062}$ operational cost minimization of the electricity ${ }^{1063}$ generation system by means of a unit commit- ${ }^{1064}$ ment and economic dispatch model. The sec- ${ }^{1065}$ ond perspective is that of a set of building own- 1066 ers which each possess a model predictive con- 1067 troller for their heating system. By modeling 1068 the two perspectives, an assessment is possi-1069 ble of reductions in both operational costs and 1070 $\mathrm{CO}_{2}$ emissions due to load shifting. Addition- 1071 ally, an integrated formulation of the two per- 1072 spectives is employed in order to determine the 1073 upper bound of operational cost and $\mathrm{CO}_{2}$ emis- 1074 sion reductions. Note that perfect predictions 1075 and absence of model mismatch are assumed in this study.

In the studied cases, this integrated formulation shows reductions in operational costs between $0.9 \%$ and $5.5 \%$, depending on the number of participating buildings and the share of RES in the electricity generation. In addition, a reduction of $\mathrm{CO}_{2}$ emissions is observed to be between $0.4 \%$ and $6.6 \%$. These savings result from a better part-load operation of the power plants, a reduction in starting up and ramping of power plants and the reduction in curtailment of electricity generation from RES.

Multiple scenarios for a more practical load shifting application are studied, inspired by time-of-use pricing and direct-load control. The added value of the integrated formulation is shown, as it produces price profiles that clearly outperform price profiles coming from the electricity generation system optimization alone. However, as soon as a large amount of buildings, identified to be 100,000 in this study, start participating in load shifting, the performance of price profiles drops significantly.

In general, and surely for a large amount of participants, it is shown that Load Shaping clearly outperforms the price-based incentives. Load Shaping gives clear information on the magnitude of RES curtailment and inefficient part-load operation of electricity generation plants. For this scheme, it does not matter how many buildings are participating, the performance remains in the same order of magnitude.

Finally, the authors suggest that a practical implementation of this load shifting approach may be performed centrally, namely by performing the day-ahead optimization of the operation of the electricity generation system and an aggregated formulation of the building portfolio with heat pumps. The resulting load profile can then be communicated to the buildings as a suggestion on how to shape the heat pump electricity demand over time. 


\section{Acknowledgement}

Dieter Patteeuw, gratefully acknowledges the KU Leuven for funding this work in the framework of his $\mathrm{PhD}$ within the GOA project 'Fundamental study of a greenhouse gas emission-free energy system'. The authors would like to thank Kenneth Bruninx, Kenneth 1105 Van Den Bergh and Erik Delarue for providing 1106 data and advice on the Belgian electricity gen-1107 eration system. The authors also thank Ken-1108 neth Bruninx and Anthony R. Florita for care- 1109 ful review of the manuscript. The computa-1110 tional resources and services used in this work 1111 were provided by the Hercules Foundation and 1112 the Flemish Government- department EWI. $\quad 1113$

\section{Appendix A. Integrated model}

The integrated model combines the electric- ${ }^{1117}$ ity generation system model with an optimal ${ }^{1118}$ control formulation of the buildings with heat ${ }^{1119}$ pumps. First, the equations of the electricity ${ }^{1120}$ generation system model are given, which are based on Van den Bergh et al. [26]. The optimization criterion is to minimize total operational cost over all timesteps with index $j$ :

$$
\min \sum_{i} \sum_{j} f c_{i, j}+c o_{2} t_{i, j}+s c_{i, j}+r c_{i, j} .
$$

For each power plant with index $i$, the generation level $\left(g_{i, j}^{P P}\right)$ and commitment status (binary variable $z_{i, j}$ ) determine the fuel cost $\left(f c_{i, j}\right), \mathrm{CO}_{2}$ cost $\left(c_{2} t_{i, j}\right)$, start-up cost $\left(s c_{i, j}\right)$ and ramping cost $\left(r c_{i, j}\right)$ :

$\forall i, \forall j: f c_{i, j}=c_{i} \cdot z_{i, j}+m a_{i} \cdot\left(g_{i, j}^{P P}-g_{i}^{m i n} \cdot z_{i, j}\right)$

(A.2) ${ }_{1121}$

$$
\begin{aligned}
\forall i, \forall j: \mathrm{CO}_{2} t_{i, j} & =c \mathrm{co}_{2} p \cdot\left[b_{i} \cdot z_{i, j}\right. \\
& \left.+m b_{i} \cdot\left(g_{i, j}^{P P}-g_{i}^{m i n} \cdot z_{i, j}\right)\right]
\end{aligned}
$$

$$
\begin{aligned}
& \forall i, \forall j: s c_{i, j}=s t c o_{i} \cdot v_{i, j} \\
& \forall i, \forall j: r c_{i, j} \geq \operatorname{raco}_{i} \cdot\left(g_{i, j}^{P P}-g_{i, j-1}^{P P}-v_{i, j} \cdot g_{i}^{\max }\right)
\end{aligned}
$$

$\forall i, \forall j: r c_{i, j} \geq r a c o_{i} \cdot\left(g_{i, j-1}^{P P}-g_{i, j}^{P P}-w_{i, j} \cdot g_{i}^{\max }\right)$

in which the binary variables $v_{i, j}$ and $w_{i, j}$ respectively denote a start-up or shut-down of power plant $i$ in time step $j$. The parameter $c_{i}$ is the fuel cost for running the plant at its minimum power level $\left(g_{i}^{m i n}\right)$ and $m a_{i}$ is the marginal cost for the generation level on top of the minimum power level. The $\mathrm{CO}_{2}$ emissions also consist of an emission $b_{i}$ at minimum power level and a term accounting for the marginal emissions $\left(m b_{i}\right)$. The $\mathrm{CO}_{2}$ cost is then determined via a $\mathrm{CO}_{2}$ price $\mathrm{co}_{2} p$. Furthermore, stco $_{i}$ and $\mathrm{raco}_{i}$ respectively denote the start-up cost and ramping cost of power plant $i$. The power plants are submitted to a series of technical constraints, different per fuel and technology:

$$
\begin{aligned}
& \forall i, \forall j: g_{i, j}^{P P} \leq g_{i}^{\max } \cdot z_{i, j} \\
& \forall i, \forall j: g_{i, j}^{P P} \geq g_{i}^{\min } \cdot z_{i, j}
\end{aligned}
$$

$$
\begin{aligned}
& \forall i, \forall j: g_{i, j}^{P P} \leq g_{i, j-1}^{P P}+\Delta_{i}^{\text {max }, \text { up }} \\
& \forall i, \forall j: g_{i, j}^{P P} \geq g_{i, j-1}^{P P}-\Delta_{i}^{\text {max }, \text { down }}
\end{aligned}
$$

$$
\begin{aligned}
& \forall i, \forall j: 1-z_{i, j} \geq \sum_{j^{\prime}=j+1-m d t_{i}}^{j} w_{i, j^{\prime}} \\
& \forall i, \forall j: z_{i, j} \geq \sum_{j^{\prime}=j+1-m u t_{i}}^{j} v_{i, j^{\prime}} \\
& \forall i, \forall j: z_{i, j-1}-z_{i, j}+v_{i, j}-w_{i, j}=0
\end{aligned}
$$

with $g_{i}^{\max }$ the maximum power level. The maximum ramping-up $\left(\Delta_{i}^{\max , u p}\right)$ and maximum ramping-down $\left(\Delta_{i}^{\text {max,down }}\right)$ values are derived from the maximum ramping rates of the power plants. The minimum up-time and down-time 


$$
\forall j: d_{j}^{\text {trad }}+n b \cdot d_{j}^{H P}=c u r_{j} \cdot g_{j}^{R E S}+\sum_{i} g_{i, j}^{P P}
$$

$$
\forall j: \quad 0 \leq \operatorname{cur}_{j} \leq 1
$$

of power plant $i$ are denoted by $m u t_{i}$ and $m d t_{i 154}$ respectively.

The market clearing condition couples the 1156 electricity generation system model and the op- 1157 timal control formulation of the buildings with 1158 heat pumps:

with cur $_{j}$ determining the amount of curtail-1161 ment of the electricity generation $\left(g_{j}^{R E S}\right)$. The 1162 demand consists of the traditional electricity ${ }_{1163}$ demand $\left(d_{j}^{\text {trad }}\right)$ to which the scaled up (with factor $n b)$ demand of the heat pumps $\left(d_{j}^{H P}\right)_{1165}^{1164}$ is added. The following equations denote the optimal control formulations of the buildings with heat pumps, as described by Patteeuw and Helsen [34. The demand $d_{j}^{H P}$ is a sum of the electricity demand of multiple buildings ${ }_{1167}^{1166}$ with index $s$ :

$$
\sum_{j} d_{j}^{H P}=\sum_{s}\left(p_{s, j}^{H P}+p_{s, j}^{A U X}\right)
$$

and consists of the positive electricity demand 1174 of the heat pump $p_{s, j}^{H P}$ and an auxiliary electri-1175 cal resistance heater $p_{s, j}^{A U X}$. These positive de- ${ }^{1176}$ mands are split up over delivering space heat-1177 ing (suffix $s h$ ) and DHW (suffix $d h w$ ) and are 1178 limited as follows

$$
\begin{aligned}
& \forall j: p_{s, j}^{H P, s h}+p_{s, j}^{H P, d h w} \leq p^{H P, \max } \\
& \forall j: p_{s, j}^{A U X, s h}+p_{s, j}^{A U X, d h w} \leq p^{A U X, \max }
\end{aligned}
$$

with $p^{H P, \max }$ the maximum electric power of the heat pump which is predetermined and fixed each optimization horizon. The heat pumps are assumed to modulate perfectly. The maximum power of the auxiliary heater
$\left(p^{A U X, \max }\right)$ is always the same value. As opposed to Eq. (6), the state space model for building and DHW tank are split up in this appendix. The state space model of the building, with temperature states $t_{s, j+1}^{s h}$ and state space matrices $\mathbf{A}^{s h}$ and $\mathbf{B}^{s h}$, is as follows

$$
\begin{aligned}
& \forall s, j: t_{s, j+1}^{s h}=\mathbf{A}^{s h} \cdot t_{s, j}^{s h} \\
& +\mathbf{B}^{s h} \cdot\left[p_{s, j}^{H P, s h}, p_{s, j}^{A U X, s h}, t_{j}^{E}, t_{j}^{G}, q_{j}^{S}, q_{s, j}^{I}\right]
\end{aligned}
$$

and is submitted to the disturbances of ambient temperature $\left(t_{j}^{E}\right)$, solar heat gain $q_{j}^{S}$ and internal heat gains $q_{s, j}^{I}$. Some of the temperature states are constrained by minimum $\left(t_{s, j}^{s h, m i n}\right)$ and maximum $\left(t_{s, j}^{s h, \max }\right)$ temperatures in order to maintain thermal comfort

$$
\forall s, j: t_{s, j}^{s h, \min } \leq t_{s, j} \leq t_{s, j}^{s h, \max } .
$$

The DHW tank is assumed to be a perfectly mixed storage tank. This tank could be heated up above the maximum temperature that the heat pump can attain $\left(t_{\max }^{h p}\right)$ by the auxiliary heater. In order to avoid the need for an integer variable, Patteeuw and Helsen 34 formulated a linear alternative. This defines the tank temperature $t_{s, j}^{\text {tank }}$ as the sum of a temperature which is influenced by the heat pump $t_{s, j}^{h p}$ and a temperature difference influenced by the auxiliary heater $d t_{s, j}^{a u x}$ (the latter for the temperature range above $t_{\max }^{h p}$, typically $60^{\circ} \mathrm{C}$ ). The model equations are:

$$
\begin{aligned}
& \forall s, j: \rho c_{p} v_{s}^{\text {tank }} \frac{1}{\Delta t}\left(t_{s, j+1}^{h p}-t_{s, j}^{h p}\right)=p_{s, j}^{a u x 1, d h w} \\
& +\operatorname{cop}^{d h w} \cdot p_{s, j}^{H P, d h w}-\dot{q}_{s, j}^{h p, d e m}-u a_{s} \cdot\left(t_{s, j}^{h p}-t^{s u r r}\right)
\end{aligned}
$$

$$
\begin{aligned}
& \forall s, j: \rho c_{p} v_{s}^{\operatorname{tank}} \frac{1}{\Delta t}\left(d t_{s, j+1}^{a u x}-d t_{s, j}^{a u x}\right)=p_{s, j}^{a u x 2, d h w} \\
& -\dot{q}_{s, j}^{a u x, d e m}-u a_{s} \cdot\left(d t_{s, j}^{a u x}\right)
\end{aligned}
$$


with $\rho$ and $c_{p}$ respectively the density and heat 1212 capacity of water. The time step is denoted as ${ }^{1213}$ $\Delta t$. The COP for delivering DHW (cop $\left.{ }^{d h w}\right)$ is ${ }^{1214}$ predetermined and assumed constant through- ${ }_{1216}$ out the optimization horizon. The DHW tank 1217 in each building with index $s$ has a certain ${ }^{1218}$ volume $v_{s}^{\text {tank }}$ and thermal conductance $u a_{s}^{\text {tank }} \cdot{ }^{1219}$ Further constraints are

$$
\begin{array}{lr}
\forall s, j: \dot{q}_{s, j}^{\text {hpdem }}+\dot{q}_{s, j}^{\text {aux dem }}=\dot{q}_{s, j}^{\text {dem }} & (\mathrm{A} .24)^{1224} \\
\forall s, j: p_{s, j}^{\text {aux } 1, \text { dhw }}+p_{s, j}^{\text {aux } 2, d h w}=p_{s, j}^{A U X, d h w} & { }^{1225} \\
& (\mathrm{~A} .25)^{1227} \\
& { }_{1228} \\
\forall s, j: t_{s, j}^{h p} \leq t_{\text {max }}^{\text {hp }} & (\mathrm{A} .26)^{1229} \\
\forall s, j: t_{s, j}^{\text {hp }} \geq t^{\text {dem }} \cdot h w d_{j}+t^{\text {cold }} \cdot\left(1-h d w_{s, j}\right)^{1230} & { }^{1231} \\
\forall s, j:\left(t_{\text {max }}^{\text {tank }}-t_{\text {max }}^{\text {hp }}\right) \geq d t_{s, j}^{\text {aux }} \geq 0 . & (\mathrm{A} .27)^{1232} \\
& (\mathrm{~A} .28)^{1233} \\
&
\end{array}
$$

The heat demand $\dot{q}_{j}^{d e m}$ for supplying DHW has ${ }^{1236}$ to be extracted either from the tank temper- ${ }^{1237}$ ature influenced by the heat pump $\left(\dot{q}_{j}^{h p, d e m}\right)_{1239}^{1238}$ or from the temperature difference influenced 1240 by the auxiliary heater $\left(\dot{q}_{j}^{\text {aux }, d e m}\right)$. The heat ${ }^{1241}$ pump can hence only heat up $t_{s, j}^{h p}$ to $t_{m a x}^{h p}$. The ${ }_{1243}^{1242}$ auxiliary heater can supply heat to both the 1244 tank temperature influenced by the heat pump ${ }^{1245}$ $\left(p_{s, j}^{a u x 1, d h w}\right)$ and the temperature difference in- ${ }_{1247}{ }^{1246}$ fluenced by the auxiliary heater $\left(p_{s, j}^{a u x 2, d h w}\right) .1248$ Finally, $t_{\text {max }}^{\text {tank }}$ denotes the maximum allowable ${ }^{1249}$ DHW tank temperature, $t^{\text {cold }}$ the temperature ${ }_{1251}^{1250}$ of cold tap water and $t^{\text {dem }}$ the minimum tank 1252 temperature needed when occupants demand ${ }^{1253}$ hot water (denoted by the boolean $h d w_{s, j}$ ). ${ }^{1254}$

\section{Appendix B. References}

[1] X. He, L. Hancher, I. Azevedo, N. Keyaerts, 1259 L. Meeus, J.-M. Glachant, Shift, not drift: to- ${ }^{1260}$ wards active demand response and beyond, Tech. ${ }_{1262}$ rep., THINK project (2013).

URL http://www.eui.eu/Projects/THINK/ ${ }_{1264}^{1263}$ Documents/Thinktopic/Topic11digital.pdf 1264

[2] G. Strbac, Demand side management: Benefits ${ }^{1265}$ and challenges, Energy policy 36 (12) (2008) $4419-{ }^{1266}$ 4426 .
[3] C. Gellings, The concept of demand-side management for electric utilities Proceedings of the IEEE 73 (10) (1985) 1468-1470.

URL http://ieeexplore.ieee.org/xpls/abs_ all.jsp?arnumber $=1457586$

[4] P. Palensky, D. Dietrich, Demand side management: Demand response, intelligent energy systems, and smart loads, Industrial Informatics, IEEE Transactions on 7 (3) (2011) 381-388.

[5] J. Wang, M. Biviji, W. M. Wang, et al., Lessons learned from smart grid enabled pricing programs, in: Power and Energy Conference at Illinois (PECI), IEEE, 2011, pp. 1-7.

[6] B. Dupont, Residential demand response based on dynamic electricity pricing: Theory and practice, Ph.D. thesis, KU Leuven, Belgium (2015).

[7] M. H. Albadi, E. El-Saadany, A summary of demand response in electricity markets, Electric power systems research 78 (11) (2008) 1989-1996.

[8] Grand View Research, Smart thermostat market analysis by technology (Wi-Fi, ZigBee) and segment forecasts to 2022 , Tech. rep. (September 2015).

URL http://www.grandviewresearch.com/ industry-analysis/smart-thermostat-market

[9] J. Lu, T. Sookoor, V. Srinivasan, G. Gao, B. Holben, J. Stankovic, E. Field, K. Whitehouse, The smart thermostat: using occupancy sensors to save energy in homes, in: Proceedings of the 8th ACM Conference on Embedded Networked Sensor Systems, ACM, 2010, pp. 211-224.

[10] Y. Matsuoka, Our first rush hour rewards results. Online (July 2013).

URL https://nest.com/blog/2013/07/18/ our-first-rush-hour-rewards-results/

[11] D. S. Callaway, Tapping the energy storage potential in electric loads to deliver load following and regulation, with application to wind energy, Energy Conversion and Management 50 (5) (2009) $1389-1400$.

[12] J. Mathieu, M. Dyson, D. Callaway, A. Rosenfeld, Using residential electric loads for fast demand response: The potential resource and revenues, the costs, and policy recommendations, in: Proceedings of the ACEEE Summer Study on Buildings, Pacific Grove, CA, 2012, pp. 189-203.

[13] D. Wang, S. Parkinson, W. Miao, H. Jia, C. Crawford, N. Djilali, Online voltage security assessment considering comfort-constrained demand response control of distributed heat pump systems, Applied Energy 96 (2012) 104-114.

[14] K. Hedegaard, B. V. Mathiesen, H. Lund, P. Heiselberg, Wind power integration using individual heat pumps - analysis of different heat storage options, Energy 47 (1) (2012) 284-293.

[15] J. Barton, S. Huang, D. Infield, M. Leach, 
D. Ogunkunle, J. Torriti, M. Thomson, The evolu- 1324 tion of electricity demand and the role for demand 1325 side participation, in buildings and transport, En- 1326 ergy Policy 52 (2013) 85-102.

[16] M. Kamgarpour, C. Ellen, S. Esmaeil, Z. Soudjani, 1328 S. Gerwinn, J. L. Mathieu, M. Nils, A. Abate, D. S. 1329 Callaway, M. Fr, Modeling Options for Demand 1330 Side Participation of Thermostatically Controlled 1331 Loads, in: IREP Symposium-Bulk Power System 1332 Dynamics and Control -IX (IREP), August 25-30, 1333 2013, Rethymnon, Greece, 2013, pp. 1-15. 1334

[17] G. P. Henze, C. Felsmann, G. Knabe, Evaluation 1335 of optimal control for active and passive building 1336 thermal storage, International Journal of Thermal 1337 Sciences 43 (2) (2004) 173-183.

$18]$ N. J. Kelly, P. G. Tuohy, A. D. Hawkes, Perfor-1339 mance assessment of tariff-based air source heat 1340 pump load shifting in a UK detached dwelling fea- 1341 turing phase change-enhanced buffering, Applied 1342 Thermal Engineering.

1343 URL http://dx.doi.org/10.1016/j.1344 applthermaleng.2013.12.019 1345

[19] N. Lu, D. P. Chassin, A state-queueing model of 1346 thermostatically controlled appliances, Power Sys- 1347 tems, IEEE Transactions on 19 (3) (2004) 1666-1348 1673.

[20] F. Oldewurtel, A. Ulbig, A. Parisio, G. Anders- 1350 son, M. Morari, Reducing peak electricity demand 1351 in building climate control using real-time pric-1352 ing and model predictive control, in: Decision and 1353 Control (CDC), 49th IEEE Conference on, pp. 1354 1927-1932.

1355

[21] B. Dupont, C. De Jonghe, L. Olmos, R. Belmans, 1356 Demand response with locational dynamic pricing 1357 to support the integration of renewables, Energy 1358 Policy 67 (2014) 344-354.

1359

$22]$ B. Dupont, K. Dietrich, C. De Jonghe, A. Ramos, 1360 R. Belmans, Impact of residential demand re-1361 sponse on power system operation: A Belgian case 1362 study, Applied Energy 122 (2014) 1-10.

[23] D. Patteeuw, G. Reynders, K. Bruninx, C. Pro- 1364 topapadaki, E. Delarue, W. D'haeseleer, D. Sae- 1365 lens, L. Helsen, $\mathrm{CO}_{2}$-abatement cost of residen- 1366 tial heat pumps with active demand response: 1367 demand- and supply-side effects, Applied Energy 1368 156 (2015) 490 - 501.

1369

[24] J. Širokỳ, F. Oldewurtel, J. Cigler, S. Prívara, Ex- 1370 perimental analysis of model predictive control for 1371 an energy efficient building heating system, Ap- 1372 plied Energy 88 (9) (2011) 3079-3087.

1373

[25] M. C. Ferris, R. Jain, S. Dirkse, GDXMRW :1374 Interfacing GAMS and MATLAB (2011). 1375 URL http://www.gams.com/dd/docs/tools/1376 gdxmrw.pdf 1377

[26] K. Van den Bergh, K. Bruninx, E. Delarue, 1378 W. D'haeseleer, LYSUM: a mixed-integer linear 1379 formulation of the unit commitment problem, KU Leuven Energy Institute Working papers EN2014-07 (2014) 1-20.

URL http://www.mech.kuleuven.be/en/ tme/research/energy_environment/Pdf/ wpen2014-07.pdf

[27] D. Patteeuw, K. Bruninx, E. Delarue, L. Helsen, W. D'haeseleer, Short-term demand response of flexible electric heating systems : an integrated model, KU Leuven Energy Institute Working Paper WP2014-28 (2014).

URL http://www.mech.kuleuven.be/en/ tme/research/energy_environment/Pdf/ wpen2014-28.pdf

[28] ENTSO-E, Internal document (2013).

[29] K. Bruninx, E. Delarue, W. Dhaeseleer, The cost of wind power forecast errors in the belgian power system, in: 2nd BAEE Research Workshop,(Leuven, Belgium), 2013, pp. 1-20.

[30] ELIA, Grid data (2013). URL http://www.elia.be/nl/grid-data

[31] A. Schröder, F. Kunz, J. Meiss, R. Mendelevitch, C. Von Hirschhausen, Current and prospective costs of electricity generation until 2050, DIW Data Documentation 68.

[32] D. Devogelaer, J. Duerinck, D. Gusbin, Y. Marenne, W. Nijs, M. Orsini, M. Pairon, Towards $100 \%$ renewable energy in Belgium by 2050, VITO, Mol (2013, April).

[33] G. Reynders, J. Diriken, D. Saelens, Bottom-up modelling of the Belgian residential building stock: influence of model complexity, in: International Conference on System Simulation in Buildings Edition 9, Liège, Belgium, 2014, pp. 574-592.

[34] D. Patteeuw, L. Helsen, Residential buildings with heat pumps, a verified bottom-up model for demand side management studies, in: International Conference on System Simulation in Buildings Edition 9, Liège, Belgium, 2014, pp. 498-516.

[35] C. Protopapadaki, G. Reynders, D. Saelens, Bottom-up modelling of the Belgian residential building stock: impact of building stock descriptions, in: International Conference on System Simulation in Buildings Edition 9, Liège, Belgium, 2014, pp. 652-672.

[36] R. Baetens, D. Saelens, Modelling uncertainty in district energy simulations by stochastic residential occupant behaviour, Journal of Building Performance Simulation (2015) 1-17doi:10.1080/ 19401493.2015.1070203

[37] I. Richardson, M. Thomson, D. Infield, A highresolution domestic building occupancy model for energy demand simulations, Energy and buildings 40 (8) (2008) 1560-1566

[38] W. Cyx, N. Renders, M. Van Holm, S. Verbeke, IEE TABULA typology approach for build- 
ing stock energy assessment, Tech. rep., VITO, Vlaamse instelling voor technologisch onderzoek (2011).

[39] G. Verbeeck, Optimisation of extremely low energy residential buildings, phd-thesis, K.U.Leuven, Belgium (2007).

[40] K. Bettgenhäuser, M. Offermann, T. Boermans, M. Bosquet, J. Grözinger, B. von Manteuffel, N. Surmeli, Heat pump implementation scenarios until 2030, appendix, Tech. rep., Ecofys (2013).

[41] C. Verhelst, F. Logist, J. Van Impe, L. Helsen, Study of the optimal control problem formulation for modulating air-to-water heat pumps connected to a residential floor heating system, Energy and Buildings 45 (2012) 43-53.

[42] D. Patteeuw, K. Bruninx, A. Arteconi, E. Delarue, W. Dhaeseleer, L. Helsen, Integrated modeling of active demand response with electric heating systems coupled to thermal energy storage systems, Applied Energy 151 (2015) 306-319.

[43] C. D. Corbin, G. P. Henze, Residential HVAC as a supply following resource part i: Simulation framework and model development, IEEE Transactions on Power Systems.

[44] C. D. Corbin, G. P. Henze, Residential HVAC as a supply following resource part ii: Simulation studies and results, IEEE Transactions on Power Systems.

[45] D. Dallinger, M. Wietschel, Grid integration of intermittent renewable energy sources using priceresponsive plug-in electric vehicles, Renewable and Sustainable Energy Reviews 16 (5) (2012) 33703382 .

[46] A. Arteconi, D. Patteeuw, K. Bruninx, E. Delarue, W. Dhaeseleer, L. Helsen, Active demand response with electric heating systems: impact of market penetration, Submitted to Energy (2015) 1-19.

[47] C. D. Corbin, Assessing impact of large-scale distributed residential HVAC control optimization on electricity grid operation and renewable energy integration, Ph.D. thesis, University of Colorado, CO, U.S.A. (2014).

[48] K. Hedegaard, M. Münster, Influence of individual heat pumps on wind power integration-energy system investments and operation, Energy Conversion and Management 75 (2013) 673-684.

[49] FPS Economy Belgium, Structure of the population according to households: per year, region and number of children, Online: http://statbel.fgov.be/nl/statistieken/ cijfers/bevolking/structuur/huishoudens/. 